\title{
Foreword: What Behavioral Scientists Are Unwilling to Accept by Lewis Petrinovich
}

\author{
Aurelio José Figueredo \\ University of Arizona
}

There are multiple levels of backstory to this paper. I was among the last few doctoral students trained by Professor Lewis ("Lew") Franklin Petrinovich, and collaborated with him on various research projects for decades after I received my $\mathrm{PhD}$ in Comparative Psychology, so I witnessed the whole origin story for this paper unfold over the years.

While still a graduate student at the University of California at Riverside, I took the course that Lew regularly taught on research methodology. I still consider that one course to be the biggest eye-opener of my graduate training. It revolutionized my thinking on how to do science and has continued to influence my professional career as a researcher in psychology. The joint influence of Lew's course and training in advanced statistics by Lew's friend and collaborator Professor Keith Widaman have shaped my subsequent approach to science, in both my research and teaching. I now realize these courses were probably designed to dovetail with each other.

I was therefore quite happy to learn years ago that Lew was writing an early draft of the present paper, setting forth his ideas on what was right and what was wrong with contemporary research in the psychological sciences. Not that all of these ideas originated with Lew. They were solidly based on the seminal work of previous methodologists, including great psychologists like Egon Brunswik, Don Campbell, and Paul Meehl, as well as great philosophers of science like Karl Popper, Imré Lakatos, and Larry Laudan. Nevertheless, the synthesis of these ideas that Lew offered was unique; I had not seen it duplicated by anyone else either before or since then.

The bad news was that the title of this paper proved prophetic: Behavioral scientists were indeed unwilling to accept his critique (and most apparently still are), and the manuscript was rejected from every journal to which he submitted it. Finally, Lew appeared to have given up and stopped even trying to get it published.

Because I remained convinced of the great value of these ideas, however, I made a photocopy of the last version of this manuscript that Lew had sent me. I included this photocopy in a packet of readings that I assigned to the students in my own classes once I began teaching at the University of Arizona. It was this old, dog-eared copy that my former graduate student, Alexander Weiss, now a Senior Lecturer (Associate Professor) in Psychology at the University of Edinburgh, somehow 
exhumed from his class notes, converted to a cleaned-up PDF, and posted on our Ethology and Evolutionary Psychology (EEP) Laboratory listserv. Alex and I then approached the Editor of the Journal of Methods and Measurement in the Social Sciences, Dr Melinda ("Mende") Fritchoff Davis, to see if we could get this paper finally published while Lew, who had recently turned 91 years of age, was still alive to give the requisite permission. Mende was thrilled by the paper, and we contacted Lew, who was quite pleased to give his consent. Now, after the appropriate process of peer review, here it is for your edification.

Reading this paper again after all these years reinforced in my mind how much it had shaped my subsequent teaching. I had wondered, after Alex discovered his old photocopy, why I had stopped assigning the original manuscript, which had begun bordering on illegible over the years. I now realize that virtually all of this material has been incorporated into the class notes I currently use for my various graduate courses in advanced statistics and research methods, including having the list of references assigned as readings, forming the essential foundation of my teaching.

A note on the name of the EEP Lab as it relates to the backstory of present interest: Both Lew and I (and, Alex) are "Comparative Psychologists", meaning animal behaviorists based in Psychology rather than Biology Departments. One might therefore wonder why all three of us were so obsessed with methodological concerns. The answer is that much of Lew's work in comparative psychology was based on an extensive methodological critique and empirical reexamination of the classic work by Peter Marler on the behavioral biology of song development in the white-crowned sparrow (Zonotrichia leucophrys). Lew's insistence of the importance of representative design, a concept he learned directly from Egon Brunswik while a graduate student at the University of California at Berkeley, led him to question Marler's results based on tapetutoring of young white-crowned sparrows in the laboratory. For those readers born in the digital era, "tape" is the physical medium that we used to record sound in those days. In collaboration with Professor Luis Felipe Baptista, Lew showed that such tape-tutoring did not adequately represent the natural song-learning environments of young birds, and that learning more naturalistically from a live social tutor quite dramatically changed many of the basic parameters of vocal development. Simply put, the change in research methodology produced different results and fundamentally rewrote what we know of vocal development in many bird species. For example, this principle also applies to song development in the Zebra finch (Taeniopygia guttata), a colonial and phylogenetically distant species from Australia to which Dr Vanya Alessandra Moreno (then a graduate student) and I subsequently applied similar methods of representative quasi-experimental design (in a fully colonial setting) and 
obtained similarly discrepant results to those obtained by laboratorybased tape-tutoring.

These experiences impressed upon all of us the critical importance of using proper research methodology within comparative psychology. Lew extended the lessons learned to psychology in general and taught others to do likewise. The present paper is a product of that line of thinking in that it examines the structural problems inherent in much of contemporary psychological research (surprisingly, now as well as then) and addressed how to begin to correct them by the simple application of superior and more well-considered methods. I consider the present paper to be the culmination of much of Lew's work, including his past research in the study of animal behavior. Regrettably, Lew passed away on 28 July 2021, and will not be with us to see this work finally published. May they toast his deeds in Valhalla! 